\title{
Controlling the Structure and Electrochemical Properties of Anode Prepared from Phenolic Resin for Li-ion Batteries
}

\author{
Zan Zhou ${ }^{1}$, Zhiqiang $\mathrm{Gu}^{1}$, Yuede He ${ }^{1^{*}}$, Dachun Peng ${ }^{l}$, Chenguang Bao ${ }^{1}$, Hongbo Liu ${ }^{1,2 * *}$ \\ ${ }^{1}$ College of Materials Science and Engineering, Hunan University, Changsha, China \\ ${ }^{2}$ Hunan Province Key Laboratory for Advanced Carbon Materials and Applied Technology, Hunan \\ University, Changsha, Hunan, 410082, China \\ *E-mail: heyuede@163.com (Yuede He); hndxlhb@163.com (Hongbo Liu);
}

doi; $10.20964 / 2019.07 .79$

Received: 14 March 2019 / Accepted: 2 May 2019 / Published: 10 June 2019

The type and molecular weight of precursor has significant influence on the structural characteristics and electrochemical performances of hard carbon which derived from phenolic resins. A series of hard carbon samples have been prepared by carbonization treatment of Novolak and Resole with different molecular weight under vacuum. Take advantage of the large layer spacing, more defects and unique pores distribution of the hard carbon that prepared from Resole with low molecular weight, which exhibits an excellent reversible capacity of $606 \mathrm{~mA} \mathrm{~h} \mathrm{~g}^{-1}$ and a superior rate performance.

Keywords: hard carbon; Lithium-ion batteries; phenolic resin; molecular weight; anode

\section{$\underline{\text { FULL TEXT }}$}

(C) 2019 The Authors. Published by ESG (www.electrochemsci.org). This article is an open access article distributed under the terms and conditions of the Creative Commons Attribution license (http://creativecommons.org/licenses/by/4.0/). 